\title{
IL-19 Halts Progression of Atherosclerotic Plaque, Polarizes, and Increases Cholesterol Uptake and Efflux in Macrophages
}

Khatuna Gabunia, ${ }^{*}$ Stephen Ellison, ${ }^{*}$ Sheri Kelemen, ${ }^{*}$ Farah Kako, ${ }^{*}$ William D. Cornwell, ${ }^{\dagger}$ Thomas J. Rogers,${ }^{\dagger}$ Prasun K. Datta, Mireille Ouimet, ${ }^{\S}$ Kathryn J. Moore, ${ }^{\S}$ and Michael V. Autieri*

From the Department of Physiology,* Independence Blue Cross Cardiovascular Research Center, the Center for Inflammation, Translational, and Clinical Lung Research, ${ }^{\dagger}$ and the Department of Neuroscience, ${ }^{\ddagger}$ Temple University School of Medicine, Philadelphia, Pennsylvania; and the Department of Medicine, ${ }^{\S}$ Leon H. Charney Division of Cardiology, New York University School of Medicine, New York, New York

\author{
Accepted for publication \\ December 22, 2015. \\ Address correspondence to \\ Michael V. Autieri, Ph.D., \\ Department of Physiology, \\ Independence Blue Cross Car- \\ diovascular Research Center, \\ Temple University School of \\ Medicine, Room 1050, MERB \\ 3500 N. Broad St., Philadel- \\ phia, PA 19140. E-mail: \\ mautieri@temple.edu.
}

\begin{abstract}
Atherosclerosis regression is an important clinical goal, and treatments that can reverse atherosclerotic plaque formation are actively being sought. Our aim was to determine whether administration of exogenous IL-19, a Th2 cytokine, could attenuate progression of preformed atherosclerotic plaque and to identify molecular mechanisms. $\mathrm{LDLR}^{-/-}$mice were fed a Western diet for 12 weeks, then administered rIL-19 or phosphate-buffered saline concomitant with Western diet for an additional 8 weeks. Analysis of atherosclerosis burden showed that IL-19-treated mice were similar to baseline, in contrast to control mice which showed a 54\% increase in plaque, suggesting that IL-19 halted the progression of atherosclerosis. Plaque characterization showed that IL-19-treated mice had key features of atherosclerosis regression, including a reduction in macrophage content and an enrichment in markers of $\mathrm{M} 2$ macrophages. Mechanistic studies revealed that IL-19 promotes the activation of key pathways leading to M2 macrophage polarization, including STAT3, STAT6, Kruppel-like factor 4, and peroxisome proliferatoractivated receptor $\gamma$, and can reduce cytokine-induced inflammation in vivo. We identified a novel role for IL-19 in regulating macrophage lipid metabolism through peroxisome proliferator-activated receptor $\gamma$-dependent regulation of scavenger receptor-mediated cholesterol uptake and ABCA1-mediated cholesterol efflux. These data show that IL-19 can halt progression of preformed atherosclerotic plaques by regulating both macrophage inflammation and cholesterol homeostasis and implicate IL-19 as a link between inflammation and macrophage cholesterol metabolism. (Am J Pathol 2016, 186: 1361-1374; http://dx.doi.org/10.1016/j.ajpath.2015.12.023)
\end{abstract}

Atherosclerosis is a proinflammatory disease that develops in the setting of hypercholesterolemia, in which the subendothelial accumulation of cholesterol drives a maladaptive macrophage immune response in the artery wall. A major goal of antiatherosclerotic therapy is to limit further plaque expansion and to regress existing lesions. Macrophages play dynamic roles in all stages of atherosclerosis development, ranging from uptake of retained lipoproteins, secretion of proinflammatory and anti-inflammatory cytokines, efferocytosis of apoptotic cells, and lipid homeostasis. Reflecting this functional diversity, several macrophage phenotypes have been described in atherosclerotic plaques, with the preponderance of studies showing that inflammatory M1 macrophages predominate in atherosclerosis progression, whereas reparative $\mathrm{M} 2$ macrophages predominate in regression of disease. In general, M1 macrophages are induced by proinflammatory cytokines and propagate a proinflammatory

Supported by NIH National Heart, Lung, and Blood Institute grants HL115575 and HL117724; American Heart Association grant 13GRNT1685003 (M.V.A.); American Heart Association postdoctoral fellowship 11POST7530001 (K.G.); and NIH grants DA14230, DA25532, P30DA13429, PO1 DA23860, and S10 RR27910 (T.J.R.).

Disclosures: None declared.

Portions of this work were presented as a poster at the annual Atherosclerosis, Thrombosis, and Vascular Biology Meeting, May 7-9, 2015, San Francisco, CA. 
response, whereas M2 macrophages are considered to be antiinflammatory and reparative. ${ }^{1}$ Studies in mouse models of atherosclerosis regression have shown that regressing plaques are characterized by an overall decrease in macrophage numbers and a concomitant enrichment in markers of M2 macrophages. On induction of plaque regression, plaque macrophages decreased their expression of M1-related genes, with a concomitant increase in M2-related genes. ${ }^{2,3}$ Therefore, agents that promote these markers of plaque regression are being actively investigated for the treatment of atherosclerosis.

Modulation of macrophage cholesterol homeostasis is another key step in plaque stasis and regression. ${ }^{4,5}$ Macrophages ingest modified lipoproteins such as oxidized lowdensity liproprotein (oxLDL) and are transformed into lipid-laden foam cells that persist in the arterial intima. Macrophages express scavenger receptors such as CD36 and SRA-1 that mediate the uptake of modified lipoproteins, and this is thought to be one of the earliest events in atherogenesis. ${ }^{6,7}$ In turn, regulated efflux enables the macrophage to export this excess cholesterol by the ATP-binding cassette transporters ABCA1 and ABCG1 to apolipoprotein A1 (apoA1) and high-density lipoprotein, which promotes reverse cholesterol transport back to the liver. Together, cholesterol homeostasis (uptake and efflux) are integral protective events in plaque reduction, ${ }^{8}$ and one strategy for plaque reduction would be to increase the cholesterol flux in plaque macrophages. Specifically, many of these effects are mediated by peroxisome proliferator-activated receptor (PPAR) $\gamma$, an anti-inflammatory transcription factor known to regulate cholesterol homeostasis by regulation of scavenger receptors and efflux proteins. ${ }^{9}$ PPAR $\gamma$ agonists ameliorate inflammation, and disruption of PPAR $\gamma$ results in decreased expression of receptor and transporter proteins and a concomitant reduction in oxLDL uptake. ${ }^{10,11}$ Therefore, an efficacious, multipronged approach to plaque regression would be to increase macrophage lipid uptake and efflux and to polarize macrophages to the M2 phenotype.

The Th2 arm of adaptive immunity tends to limit the magnitude of the inflammatory response, but there is little literature about Th2 cytokine regulation of cholesterol homeostasis. IL-19 is a Th2 cytokine that is a member of an IL-10 subfamily that includes IL-19, IL-20, and IL-24; however; IL-19 is functionally distinct from these subfamily members and IL-10. ${ }^{12-14}$ Previous studies from our laboratory showed that IL-19 is expressed in human atherosclerotic plaque, and treatment of atherosclerosissusceptible mice with rIL-19 significantly reduced plaque formation during Western diet (WD) feeding. ${ }^{15}$ We showed that IL-19 could reduce inflammatory gene expression in endothelial and vascular smooth muscle cells, ${ }^{16-19}$ but its effect on macrophage inflammation and lipid metabolism has not been studied. Notably, in a model of hind limb ischemia, in chow-fed mice in which there is no hyperlipidemia, we found that IL-19 treatment promoted the accumulation of M2-like macrophages. These data raised the question of whether the atheroprotective effects of IL-19 could derive, in part, from effects on macrophage polarization in plaques, particularly within the setting of hyperlipidemia, which is known to drive M1 polarization. To test this, we used a model of atherosclerosis intervention in which mice were first fed a WD to establish atherosclerotic plaques and then treated with IL-19 or vehicle for 8 weeks with continued WD feeding. Our data indicate that IL-19 can regulate both macrophage inflammation and lipid metabolism to halt the progression of preexisting atherosclerotic plaques. Furthermore, mechanistic studies reveal a key role for IL-19-mediated PPAR $\gamma$ up-regulation and activation in these processes. These data suggest that IL-19 may be a novel regulator of macrophage anti-inflammatory processes and cholesterol homeostasis in the treatment of atherosclerosis.

\section{Materials and Methods}

\section{Mice and Study Design}

LDL receptor knockout $\left(\mathrm{LDLR}^{-/-}\right.$) mice (stock no. 002207; The Jackson Laboratory, Bar Harbor, ME) of both sexes were maintained on a standard chow diet until study commencement. LDLR $^{-1-}$ were used because these mice do not develop lesion until fed a high-fat diet, allowing us to synchronize initiation of atherosclerosis with IL-19 administration. Normal chow was replaced with a WD $(42 \%$ fat, $0.2 \%$ cholesterol; Harlan atherogenic diet TD.88137; Harlan, Indianapolis, IN) for 12 weeks, and aortic arches from a cohort of these mice were examined by en face staining to establish baseline lesion accumulation. The remaining mice were maintained on a WD and injected i.p. with either phosphate-buffered saline (PBS) or $10 \mathrm{ng} / \mathrm{g}$ rIL19 per day (R\&D Inc., Minneapolis, MN), 5 days per week for an additional 8 weeks as we described. ${ }^{15}$ Wild-type C57BL/6 mice purchased from The Jackson Laboratory were used for isolation of bone marrow-derived macrophages (BMDMs). No mice were excluded from analysis. All animal procedures followed the protocols approved by Temple University Institutional Animal Care and Use Committee.

\section{Serum Lipid Analysis}

Fasting lipid content in mouse sera was analyzed by Charles River Research Animal Diagnostic Services (Wilmington, MA), as described. ${ }^{15}$

\section{Atherosclerotic Lesion Analysis}

Atherosclerotic plaque was determined in the aortic intimal surface by en face staining with Sudan IV as described. ${ }^{15}$ Aortic root was frozen in OCT medium and sectioned. Four transverse serial sections spaced 70 to $100 \mu \mathrm{m}$ apart from the aortic sinus to disappearance of valve cusps per aortic root from each mouse were stained with Oil Red O, and positive-stained lesion areas were quantitated as a 
percentage of total area by quantitative morphometry with the use of Image Pro Plus version 7.0 (Media Cybernetics, Inc., Bethesda, MD) as described. ${ }^{15}$

\section{BMDM/Primary Human Macrophage Generation}

To generate BMDMs, mouse femurs and tibiae were flushed with sterile Dulbecco's modified Eagle's medium (DMEM). Total BM cells were plated at a density of $3.5 \times 10^{6}$ cells per $10-\mathrm{cm}$ Petri dish in macrophage growth medium (complete DMEM with 10\% fetal bovine serum and $100 \mathrm{ng} /$ $\mathrm{mL}$ macrophage colony-stimulating factor; PeproTech Inc., Rocky Hill, NJ) and allowed to differentiate for seven days, after which cells were detached with Versene $1 \times$ solution (Gibco, Carlsbad, CA) and replated in macrophage complete media (DMEM $+10 \%$ fetal bovine serum).

Human blood was collected by venous puncture into blood collection tubes that contained acid citrate dextrose. Peripheral blood mononuclear cells were isolated on a Ficoll gradient, followed by washing with Hanks Balanced Salt Solution. Peripheral blood mononuclear cells were cultured in DMEM without fetal calf serum at a density of 3.5 million cells per well of a 24 -well plate for 2 hours at $37^{\circ} \mathrm{C}$ to allow the monocytes to attach to the plastic. The medium was removed, and adherent cells were washed with DMEM (without fetal calf serum). RPMI medium that contained $10 \%$ fetal calf serum, $1 \mathrm{mmol} / \mathrm{L}$ glutamine, $25 \mathrm{mmol} / \mathrm{L}$ HEPES, $10 \mu \mathrm{g} / \mathrm{mL}$ gentamicin, and $100 \mathrm{ng} / \mathrm{mL}$ human macrophage colony-stimulating factor (PeproTech Inc.) were added, and monocytes were cultured for 7 days to allow differentiation into macrophages. Macrophages were stimulated with $20 \mathrm{ng} / \mathrm{mL}$ human interferon (IFN)- $\gamma$ (PeproTech Inc.) plus $100 \mathrm{ng} / \mathrm{mL}$ lipopolysaccharide (Sigma-Aldrich, Indianapolis, IN) for 24 hours to induce the M1 phenotype or with $20 \mathrm{ng} / \mathrm{mL} \mathrm{IL-4} \mathrm{(PeproTech} \mathrm{Inc.)} \mathrm{for}$ 24 hours to induce the M2 phenotype.

\section{DiI LDL Uptake and Cholesterol Efflux}

For uptake, $1 \times 10^{6}$ BMDMs were plated in 12-well plates in DMEM $+1 \%$ bovine serum albumin, with or without 100 $\mathrm{ng} / \mathrm{mL}$ IL-19. After overnight culture macrophages were incubated in the dark with $5 \mu \mathrm{g} / \mathrm{mL} 1,1^{\prime}$-dioetadeeyl-3,3,3',3tetramethylindocarboeyanin perchlorate (DiI)-oxLDL (Kalen Biomedical, Montgomery Village, MD) for 4 hours. After incubation cells were washed 3 times with PBS, detached with Versene, and subjected to flow cytometry analysis (FACS Calibur; Becton Dickinson, Franklin Lakes, NJ) as described. ${ }^{20}$ The mean of DiI-oxLDL fluorescence intensity was obtained from 10,000 cells. Data were calculated and expressed as mean fluorescence intensity.

For cholesterol efflux assays, mouse BMDMs were incubated with $0.5 \mu \mathrm{Ci} / \mathrm{mL}^{3} \mathrm{H}$-cholesterol (PerkinElmer, Boston, $\mathrm{MA}$ ) for 24 hours, after which time they were equilibrated in $2 \mathrm{mg} / \mathrm{mL}$ bovine serum albumin overnight in the presence or absence or $100 \mathrm{ng} / \mathrm{mL} \mathrm{IL-19}$. After equilibration, cells were incubated with $50 \mu \mathrm{g} / \mathrm{mL}$ human apoA1 (Biomedical Technologies, Cambridge, MA), in the presence or absence of $100 \mathrm{ng} / \mathrm{mL}$ IL-19. Cholesterol efflux was expressed as a percentage of ${ }^{3} \mathrm{H}$-cholesterol in the supernatants $/\left({ }^{3} \mathrm{H}\right.$-cholesterol in the supernatants $+{ }^{3} \mathrm{H}$-cholesterol in cell lysates), and apoA1-specific efflux was calculated by subtracting effluxes of the wells without apoA1 from those that contained apoA1.

\section{Transfection and siRNA Knockdown}

Gene silencing was performed with ON-TARGET plus SMARTpool PPAR $\gamma$ (L-040712) and Kruppel-like factor (KLF)4 (L-040001) siRNA, which contains a mixture of four siRNAs that target mouse PPAR $\gamma$ and KLF4, respectively $(10 \mathrm{nmol} / \mathrm{L})($ Dharmacon, Inc., Lafayette, $\mathrm{CO})$ as described. ${ }^{20}$ Transfection of BMDMs was performed with the AMAXA Nucleofector Kit (Amaxa, Inc., Gaithersburg, MD) according to the manufacturer's instructions. With the use of this method transient transfection efficiency was between $70 \%$ and $90 \%$.

\section{Luciferase Assay}

BMDMs were transfected with the PPAR $\gamma$ Dual-luciferase Cignal reporter that is a luciferase reporter gene under the control of tandem repeats of the PPAR $\gamma$ transcriptional response element with the use of the AMAXA Nucleofector Kit (Amaxa, Inc.) according to the manufacturer's instructions. IL-19, $1 \mu \mathrm{mol} / \mathrm{L}$ PPAR $\gamma$ activator Rosiglitazone, or $5 \mu \mathrm{mol} / \mathrm{L}$ PPAR $\gamma$ inhibitor GW9662 were added 24 hours after transfection. BMDMs were lyzed 24 hours after incubation, and dual-luciferase reporter assays were performed with $10 \mu \mathrm{L}$ of cell lysates with the Dual-Luciferase Reporter Assay System (Promega, Madison, WI). Light emission was quantified with an FB12 Luminometer (Zylux, Oak Ridge, TN). Relative normalized luciferase activity was expressed as the ratio of firefly luciferase activity to renilla luciferase activity.

\section{Immunohistochemistry}

Aortic root was frozen in OCT medium and sectioned. Transverse serial sections from the aortic sinus to disappearance of valve cusps per aortic root were blocked in 5\% donkey serum, incubated with CD68 antibody (no. MCA1957; AbD Serotec, Raleigh, NC) at $4 \mu \mathrm{g} / \mathrm{mL}$ for 2 hours, followed by incubation with fluorescently labeled $(488 \mathrm{~nm})$ secondary antibody (no. SA5-10026; Thermo Scientific, Waltham, MA). Nonspecific identical isotype control (no. 400601; BioLegend, San Diego, CA) antibodies were used as negative controls as previously described. ${ }^{15}$ For characterization of macrophage infiltrate, four transverse serial sections spaced $50 \mu \mathrm{m}$ apart from the aortic sinus to disappearance of valve cusps per aortic root from at least seven mice in each group were immunostained. CD68 immunoreactivity was quantitated with the Image Pro Plus program as the percentage of each lesion area which that stained positive. $^{21}$ 


\section{RNA Extraction and RT-qPCR}

RNA from cultured cells, aorta, or spleen was isolated and reverse transcribed into cDNA as we have described, and target genes were amplified with an Eppendorf Realplex4 Mastercycler (Eppendorf North America, Hauppauge, NY) ${ }^{15,19}$ Briefly, tissue was homogenized in $1 \mathrm{~mL}$ of QIAzol Lysis reagent (Qiagen, Hilden, Germany), and total RNA was extracted with the RNeasy Plus Universal kit (Qiagen) according to the manufacturer's protocol. One microgram RNA from each mouse was reverse transcribed with Maxima First Strand cDNA Synthesis kit for quantitative RT-PCR (RTqPCR; Thermo Scientific). cDNA was amplified with SYBR green (Thermo Scientific) and gene-specific primers. Results were normalized with the housekeeping gene $G A P D H$ and the relative fold change in signal of IL-19 treated over control group. Multiple mRNAs (Ct values) were quantitated simultaneously by Eppendorf Realplex version 3.36 (Eppendorf North America). Primer pairs were purchased from Integrated DNA Technologies (Coralville, IA), SYBR green was used for detection. The following primer pairs were used: mouse IL-12p40: forward, 5'-GTGAAGCACCAAATTACTCCG-3' ${ }^{\prime}$, reverse, $5^{\prime}$-AGAGACGCCATTCCACATG-3'; mouse monocyte chemoattractant protein (MCP)-1: forward, $5^{\prime}$-TTAAAAACCTGGATCGGAACCAA- $3^{\prime}$, reverse, 5'-GCATTAGCTTCAGATTTACGGGT- ${ }^{\prime}$; mouse tumor necrosis factor (TNF)- $\alpha$ : forward, $5^{\prime}$-CTTCTGTCTACTGAACTTCGGG-3', reverse, 5'-CAGGCTTGTCACTCGAATTTTG-3'; mouse GAPDH: forward, 5'-GCAAGGACACTGAGCAAGAG-3', reverse, 5'GGGTCTGGGATGGAAATTGT-3'; mouse arginase 1 : forward, $5^{\prime}$-AAGAATGGAAGAGTCAGTGTGG-3' ${ }^{\prime}$, reverse, $5^{\prime}$-GGGAGTGTTGATGTCAGTGTG-3'; mouse arginase 2: 5'-forward, CAGAAGGTGATGGAACAGACA- $3^{\prime}$, reverse, 5'-GCCAGTTTAGGGTCAAATGC- $3^{\prime}$; mouse Ym1: forward, $5^{\prime}$-AGAGTGCTGATCTCAATGTGG-3', reverse, 5'-GGGCACCAATTCCAGTCTTAG-3'; mouse KLF4: forward, 5'-ACTTGTGACTATGCAGGCTG- $3^{\prime}$, reverse, 5'-ACAGTGGTAAGGTTTCTCGC- $3^{\prime}$; mouse SRB-1: forward, $5^{\prime}$-ATGATCAATGGGACTTCCGG- ${ }^{\prime}$, reverse, 5' -TGAAGCGATACGTGGGAATG-3'; mouse SRA-1: forward, 5'-GGGAACACTCACAGACACTG-3' ${ }^{\prime}$, reverse, $5^{\prime}$-CCCGATCACCTTTAACACCTG-3'; mouse CD36: forward, 5'-GCGACATGATTAATGGCACAG- $3^{\prime}$ reverse, $5^{\prime}$-GATCCGAACACAGCGTAGATAG-3'; mouse PPAR $\gamma$ : forward, 5'-GAACCTTCTAACTCCCTCATGG-3', reverse, 5'-TCAATCGGATGGTTCTTCGG-3'; mouse ABCG1: forward, 5'-TCAAGGACAATGCGTATACAGG-3', reverse, 5'-TGTTCTGATCCCCGTACTCC- $3^{\prime}$; and mouse ABCA1: forward, 5'-TGACATGGTACATCGAAGCC-3', reverse, 5'-GATTTCTGACACTCCCTTCTGG-3'

\section{Western Blot Analysis}

Protein extracts made as described separated by SDS-PAGE, transferred to nitrocellulose membrane, incubated with a 1:5000 dilution of primary antibody [KLF4, CD36, MCP-1, TNF- $\alpha$, SRA-1, SRB-1, PPAR $\gamma$, IL12p40, total and phospho-STAT3 and STAT6, GAPDH (AbCam, Cell Signaling Technology, Inc., Danvers, MA), and ABCA-1 and ABCG-1 (Novus Biologicals LLC, Littleton, CA)] and a 1:8000 dilution of secondary antibody. ${ }^{15,19,22}$ Equal loading of protein extracts on gels was verified by Ponceau $\mathrm{S}$ staining of the membrane, and blotting with the housekeeping protein anti-GAPDH (dilution 1:7000; Biogenesis Inc., Hackensack, NJ), and reactive proteins were visualized with enhanced chemiluminescence. The intensity of each band was quantitated with ImageJ software version 1.47v (NIH, Bethesda, MD; http://imagej.nih.gov/ij).

\section{STAT Inhibitors, Apoptosis Assay, Flow Cytometry}

STAT inhibition STAT3 inhibitor V, STATTIC was purchased from Santa Cruz Biotechnology (Dallas, TX) and was used at a concentration of $2.5 \mu \mathrm{mol} / \mathrm{L} .^{23}$ A second STAT3 inhibitor III, WP1066, was also purchased from Santa Cruz, Inc. and was used at a concentration of $5.0 \mu \mathrm{mol} / \mathrm{L} .{ }^{24}$ Each inhibitor was added 30 minutes before the addition of IL-19.

Caspase 3/7 activity in BMDMs was used to measure apoptosis. Briefly, a total of $2 \times 10^{4}$ mouse BMDMs were seeded in triplicate in 96-well clear plates in DMEM with $10 \%$ fetal bovine serum. After 24 hours, BMDMs were starved in DMEM that contained $1 \%$ bovine serum albumin. After 2 hours some wells were treated with IL-19, ox-LDL, or in combination for different time points, after which the activity of caspase-3/7 was detected by luminescence with the use of the Caspase-Glo 3/7 assay kit (Promega) according to the manufacturer's instructions.

To prepare single-cell suspensions from spleen for flow cytometric analysis, spleen cells were passed through a nylon strainer and lyzed for red blood cells. After incubation with Cell Stimulation Cocktail (eBioscience, Inc., San Diego, CA), cells were washed and stained with specific antibody: TCR $\beta$ (eFluor450-labeld clone H57-597; eBioscience, Inc.), CD4 (Odot 605-labeled Clone RM4-5; Invitrogen, Carlsbad, CA), followed by fixation and permeabilization (BD Cytofix/Cytoperm Fixation/permeabilization kit) and staining for IFN- $\gamma$ (allophycocyanin-labeled clone XMG1.2; eBioscience, Inc.) and IL-4 [phosphatidylethanolamine (PE)-labeled clone 11B11; eBioscience, Inc.], CD86 (allophycocyanin-labeled clone GL-1; BioLegend), and anti-CD206 (PE/cyanine 7-labeled clone C068C2; BioLegend). Splenocytes were washed, suspended in PBS, and analyzed by flow cytometry with the use of an LSR II cytometer (Becton Dickinson).

\section{Statistical Analysis}

Results are expressed as means \pm SEM. Differences between groups were evaluated with the use of analysis of variance, with the Newman-Keuls method applied to evaluate differences between individual mean values or by paired $t$-tests when appropriate. Interquartile range was determined by the GraphPad Prism statistical analysis program. Differences were considered significant when $P<0.05$. 
A

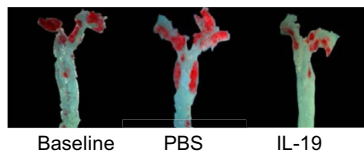

C

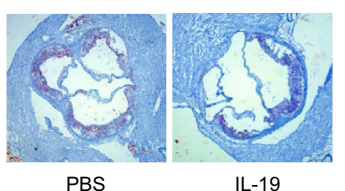

E

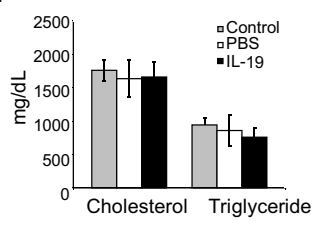

G

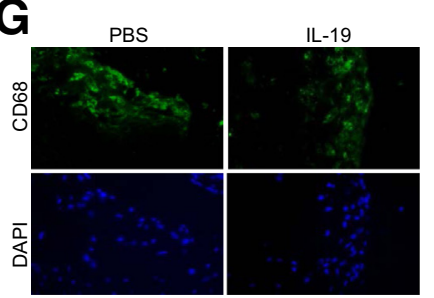

H

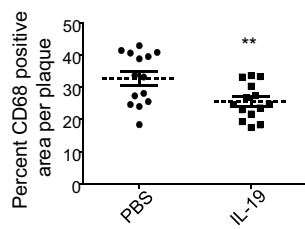

Figure 1 IL-19 administration induces plaque stasis. A: Representative photomicrograph of aortic arch from $\mathrm{LDLR}^{-/-}$mice after consuming the atherogenic diet for 12 weeks, injected with either PBS or $10 \mathrm{ng} / \mathrm{g} \mathrm{IL-19}$ per day. Surface lesion en face stained with Sudan IV. B: Graphic depiction of atherosclerotic lesion size quantitated from en face-stained aortic arches as depicted in panel A. IL-19 does not modify serum lipids or weight. C: Representative photomicrographs of aortic root stained with Oil Red 0 from mice treated with $10 \mathrm{ng} /$ g IL-19 or PBS per day. D: Quantitation of lesion area from four transverse serial sections from the aortic sinus to disappearance of valve cusps per aortic root from mice were stained with 0 il Red 0 , and positive-stained areas were quantitated. E: Cholesterol and triglycerides in mice fed an atherogenic diet for 12 weeks receiving either PBS or $10 \mathrm{ng} / \mathrm{g}$ IL-19 per day do not statistically differ between groups at time of euthanasia. F: Weight gain does not statistically differ between control and IL-19 groups. G: IL-19 reduces macrophage infiltrate in vivo. Aortic roots were recovered from mice, and lesion areas from transverse serial sections from the aortic sinus to disappearance of valve cusps per aortic root from mice were immunostained with antibody to CD68. H: Positively stained areas were quantified as a percentage of total lesion area by quantitative morphometry. Data are expressed as means \pm SEM. $n=7$ each $(\mathbf{B}, \mathbf{E}$, and $\mathbf{F}) ; n=8$ mice per group, using at least three sections per aortic root $(\mathbf{H}) .{ }^{* *} P<0.01$. LDLR $^{-1-}$, lowdensity lipoprotein receptor knockout; PBS, phosphate-buffered saline.

\section{Results}

\section{IL-19 Can Arrest the Progression of Existing Atherosclerotic Plaques}

Previous studies from our laboratory established that IL-19 can reduce the development of atherosclerotic plaques in hyperlipidemic mice fed a WD. ${ }^{15}$ However, because most patients present with existing atherosclerosis, a major clinical goal is the regression and/or stabilization of atherosclerotic plaques. $\mathrm{LDLR}^{-1-}$ mice were fed an atherogenic, WD for 12 weeks, and aortic arches from a cohort of these mice were examined by en face staining to establish baseline lesion accumulation. The remaining mice were injected either with PBS or $10 \mathrm{ng} / \mathrm{g}$ rIL-19 per day, 5 days per week, for an additional 8 weeks (Figure 1A). En face analysis of atherosclerotic burden in the aortic arches showed that mice treated with rIL-19 showed no increase in atherosclerosis compared with the baseline group $(23.35 \% \pm 2.23 \%$ versus $26.51 \% \pm 1.47 \%$ for IL-19 and baseline, respectively). This is in contrast to mice treated with PBS which had significantly greater progression of atherosclerosis $(40.91 \% \pm 2.65 \%)$ compared with both baseline $(P<0.001)$ and rIL-19 treated mice $(P<0.01)$ (Figure 1B). Lesion area assessed by quantitative morphometry in multiple serial transverse sections of Oil Red O-stained aortic root was significantly reduced in IL-19-injected mice compared with PBS controls $(38.30 \% \pm 2.92 \%$ versus $26.84 \% \pm 2.42 \%$ for PBS and IL-19 treated, respectively; $P<0.01$ ) (Figure 1, C and D and Figure 2, C and D). Notably, no significant difference was found in weight gain or serum lipid profiles among the groups of mice $(1757 \pm 156.2$, $1637 \pm 268.2,1659 \pm 223.7 \mathrm{mg} / \mathrm{dL}$ cholesterol, and $940 \pm 102.7,860.2 \pm 229.9,759.0 \pm 133.7 \mathrm{mg} / \mathrm{dL}$ triglycerides for control, PBS-, and IL-19-injected mice, respectively), indicating that IL-19 halted atherosclerosis progression in the absence of changes in these metabolic variables (Figure 1, E and F). Subsequent experiments were performed to determine the cellular and molecular mechanism(s) for this effect.

\section{IL-19 Reduces Macrophage Accumulation and Polarizes Macrophages to the M2 Phenotype}

Recent studies of atherosclerosis regression have shown that regressing plaques are characterized by both a reduction in macrophage content and a reduction in their inflammatory polarization. We next characterized the cellular content of plaques in IL-19- and PBS-treated mice by immunohistochemical staining for the macrophage marker CD68. Multiple serial sections throughout the aortic root revealed a significant reduction in macrophage accumulation in aortic sinus plaques from IL-19-treated versus PBS-treated mice $\left(32.77 \% \pm 2.14 \%\right.$ versus $25.51 \% \pm 1.27 \% \mathrm{CD}^{+} 8^{+}$area for PBS and rIL-19, respectively; $P<0.01$ ) (Figure 1, G and H). Several complementary experiments were performed with tissue from different sources to determine whether IL-19 could polarize macrophages to the M2 phenotype within the proinflammatory background of hyperlipidemia. Analysis of mRNA isolated from aortas showed that mice treated with rIL-19 had significantly increased expression of M2 markers ArgI and Ym1 and significantly decreased expression of the M1 marker $A r g 2$ compared with controls $(0.45 \pm 0.07$ versus $1.45 \pm 0.30$ for ArgI, $0.44 \pm 0.03$ versus $1.04 \pm 0.16$ for 

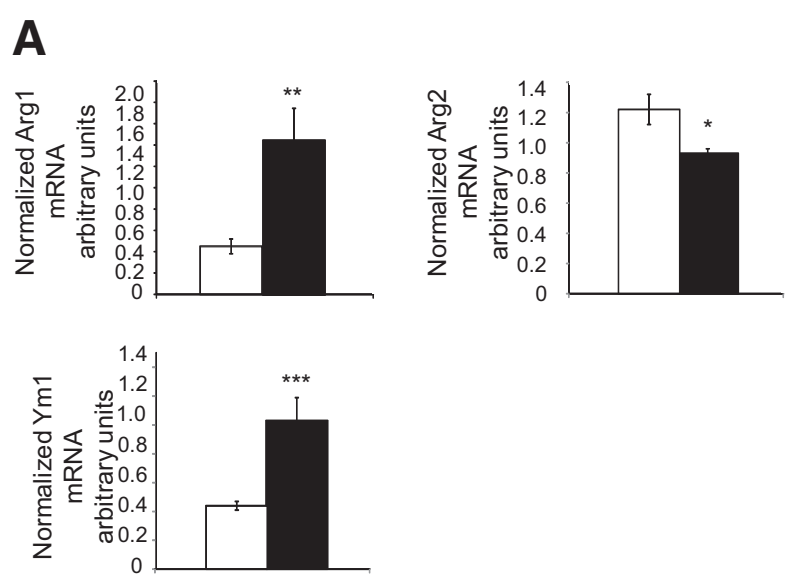

B
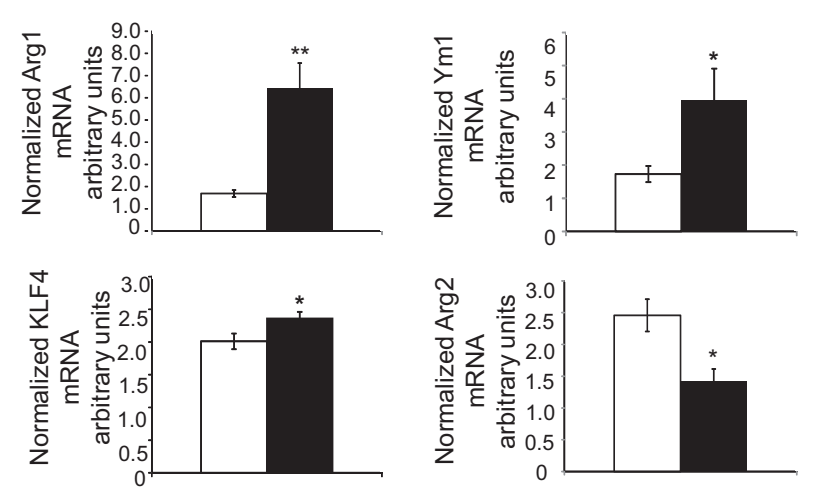

C

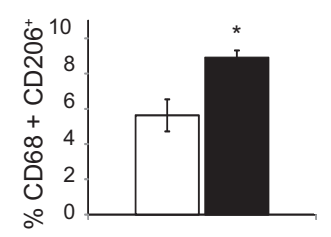

D

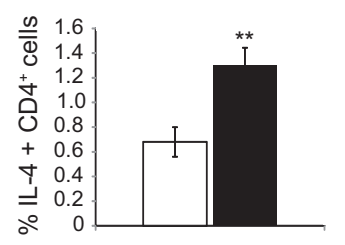

Figure 2 IL-19 polarizes plaque macrophage to the M2 phenotype. A: RT-qPCR on RNA extracted from aorta of mice removed at the end of the study which received either PBS or rIL-19. RNA was amplified with the primer pairs for the macrophage phenotypes shown. B: RT-qPCR on RNA extracted from spleen from mice receiving either PBS or $10 \mathrm{ng} / \mathrm{g}$ IL-19 per day. Spleens were removed at the end of the study, RNA was extracted, reverse transcribed, and amplified with the primer pairs shown. $\mathbf{C}$ and $\mathbf{D}$ : Increased expression of M2 macrophage markers (C) and Th2 lymphocyte markers (D) in spleen of IL-19-treated mice as detected by flow cytometry. White bars, PBS; black bars, rIL-19. Data are expressed as means \pm SEM. $n$ $=6$ aorta per group $(\mathbf{A}) ; n=6$ spleen each group $(\mathbf{C}$ and $\mathbf{D}) .{ }^{*} P<0.05$, ${ }^{* *} P<0.01$, and ${ }^{* * *} P<0.001$. PBS, phosphate-buffered saline; RT-qPCR, quantitative RT-PCR.

Ym1, and $1.22 \pm 0.10$ versus $0.93 \pm 0.03$ for ArgII; $P<0.05,0.01$, or 0.001 , respectively) (Figure $2 \mathrm{~A}$ ).

Analysis of mRNA isolated from the spleen removed at the time of atherosclerosis analysis showed that mice treated with IL-19 had significantly greater expression of M2 markers ArgI, Ym1, and KLF4 and significantly decreased expression of the M1 marker Arg2 compared with controls (1.68 \pm 0.15 versus $6.41 \pm 1.14$ for $\mathrm{ArgI}, 1.73 \pm 0.24$ versus $3.98 \pm 0.94$ for $\mathrm{Ym} 1,2.01 \pm 0.12$ versus $2.37 \pm 0.10$ for KLF4, and $2.46 \pm 0.25$ versus $1.41 \pm 0.19$ for $\operatorname{ArgII} ; P<0.01$ or 0.05 for all, respectively) (Figure 2B). Flow cytometric immune cell characterization analysis of spleen recovered at the time of sacrifice showed a significantly increased percentage of $\mathrm{CD}^{+} 8^{+} / \mathrm{CD} 206^{+}$macrophage in spleen $(5.63 \pm 0.91$ versus $8.93 \pm 0.42$ for PBS and IL-19 treated, respectively; $P<0.05$ ), pointing to $\mathrm{M} 2$ polarization, and also significantly increased percentage of $\mathrm{IL}^{+} / \mathrm{CD}^{+}{ }^{+} \mathrm{T}$ cells $(0.68 \% \pm 0.12 \%$ versus $1.30 \% \pm 0.14 \%$ for PBS and IL-19 treated, respectively; $P<0.01$ ), pointing to Th2 polarization (Figure 2, C and D). Together, these data suggest that plaques from IL19-treated mice display key features of atherosclerosis regression and that IL-19 can mediate the polarization of macrophages to the M2 phenotype in multiple tissues.

\section{IL-19 Decreases Inflammation in BMDMs}

To investigate the molecular mechanisms by which IL-19 reduces macrophage inflammation, we first determined whether IL-19 pretreatment could decrease the inflammatory response of wild-type BMDMs stimulated with TNF- $\alpha$. Quantification of mRNA expression of proinflammatory cytokines showed that IL-19 treatment significantly reduced the expression of IL-12p40, MCP-1, and TNF- $\alpha$ mRNA in BMDMs treated with TNF- $\alpha$ ( $72.1 \%$ for IL-12p40, $42.0 \%$ for MCP-1, and 52.5\% for TNF- $\alpha$ ) (Figure 3A). Furthermore, immunoblotting of cell lysates from similarly treated BMDMs confirmed the reduction of IL-12, MCP-1, and TNF- $\alpha$ protein expression by IL-19 (Figure 3, B and C). Together these data indicate that IL-19 reduces markers of M1 polarized macrophages.

\section{IL-19 Polarizes BMDMs in a KLF4-Dependent Manner}

In an additional series of experiments to investigate whether IL-19 can polarize isolated macrophages to the M2 phenotype, BMDMs isolated from wild-type mice were stimulated with IL-19. We observed that IL-19 significantly increased expression of M2 phenotype markers compared with controls $(0.54 \pm 0.14$ versus $1.01 \pm 0.03$ for ArgI, $0.04 \pm 0.01$ versus $0.17 \pm 0.02$ for Ym1, and $2.81 \pm 0.35$ versus $4.71 \pm 0.17$ for KLF4; $P<0.01$ or 0.05 for all, respectively) (Figure 4A). Importantly, KLF4 is a transcription factor recently described to regulate M2 macrophage polarization, and we confirmed that IL-19 induced expression of KLF4 protein in BMDMs (Figure 4, B and C).

To determine whether IL-19 expression itself is altered during macrophage polarization, human monocytes were isolated by venipuncture, differentiated into macrophages, and cultured with IFN- $\gamma$ and lipopolysaccharide, or IL-4 to induce the M1 and M2 phenotypes, respectively. IL-19 expression was induced in M2 but not in M1 macrophages coincident with the induction of KLF4 protein (Figure 4, D and E). Together, these data suggest that IL-19 induces M2 


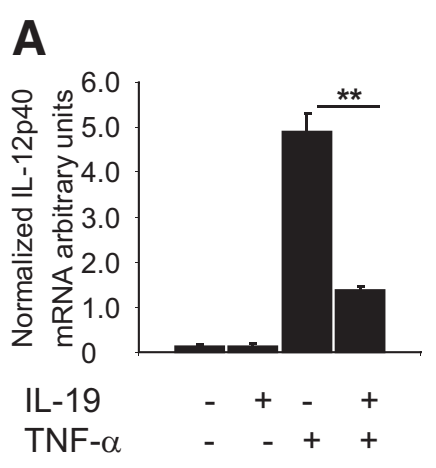

B

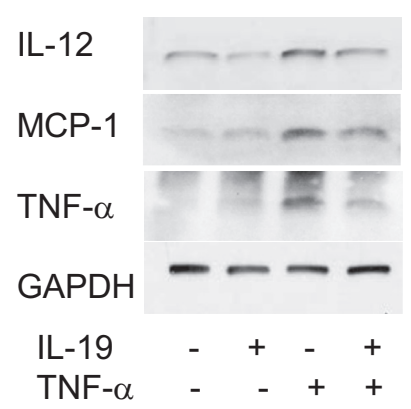

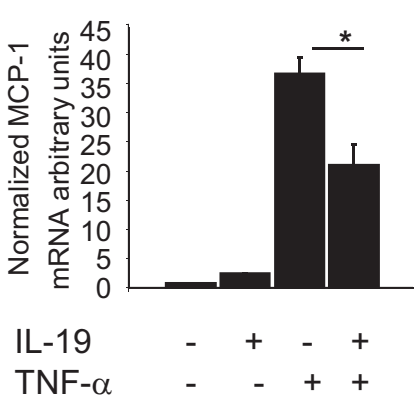
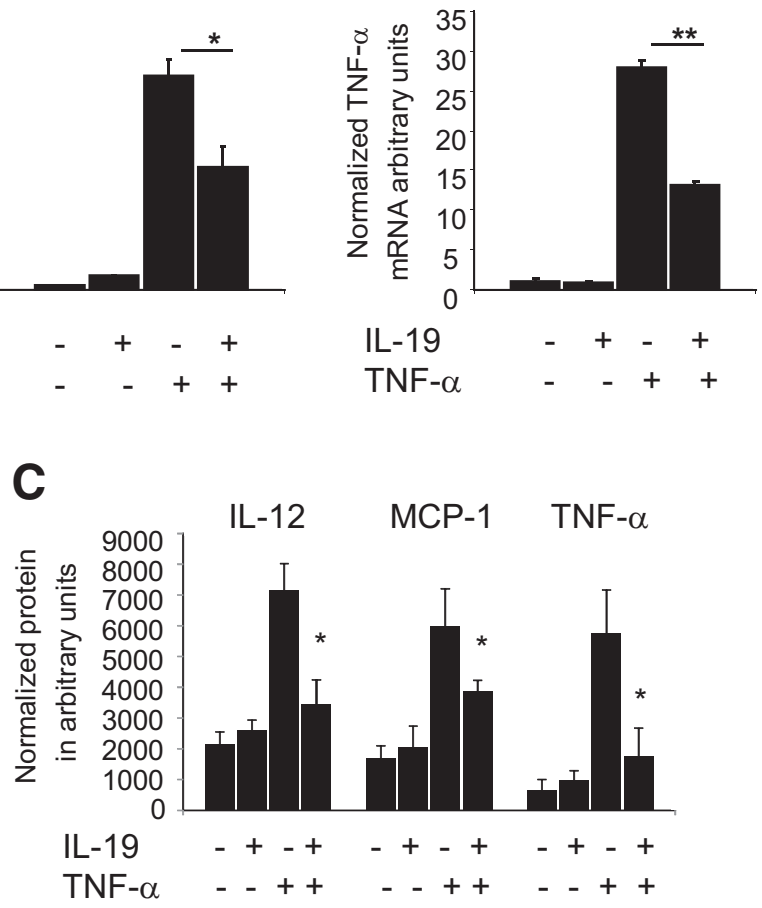

Figure 3 IL-19 reduces macrophage inflammation. A: IL-19 reduces expression of inflammatory cytokines in stimulated BMDMs. BMDMs were pretreated with IL-19 for 8 hours, then TNF- $\alpha$ to induce expression of proinflammatory cytokines. RNA was extracted and subject to quantitative RT-PCR with the use of primers for the indicated proinflammatory cytokines. B: Representative immunoblot of lysates from BMDMs treated as described above, blotted with antibody for the indicated cytokines. C: Densiometric quantification of three independent Western blot analyses of BMDMs stimulated with TNF- $\alpha$, IL-19, or together. Data are expressed as means \pm SEM. $n=3$ Western blot analyses (C). ${ }^{*} P<0.05,{ }^{*} P<0.01$. BMDM, bone marrow-derived macrophage; MCP, monocyte chemoattractant protein; TNF, tumor necrosis factor.

macrophage polarization and may promote an amplification loop through which M2 macrophages further elaborate IL-19 and induction of KLF4. To determine whether IL-19 induction of the M2 phenotype depends on KLF4 expression, BMDMs were transfected with KLF4-specific siRNA, then stimulated with IL-19, and M2 biomarker expression was quantitated by RT-qPCR. KLF4 siRNA effectively reduced KLF4 protein (Figure 4F). KLF4 knockdown significantly reduced IL-19-driven mRNA abundance of M2 phenotype-associated genes KLF4, Arg1, Ym1 (72.2\%, $72.8 \%$, and $83.5 \%$, respectively), and to a lesser, but still significant amount, PPAR $\gamma$ (18.9\%) (Figure 4, G and H).

\section{IL-19 Activates STAT Proteins and PPAR $\gamma$}

Differential STAT activation is a key molecular determinant of M2 macrophage polarization, with the M2 phenotype characterized by activation of STAT3 and STAT6. ${ }^{22,25-27}$ To test whether IL-19 alters STAT signaling we measured STAT3 and STAT6 phosphorylation in BMDMs treated with IL-19 for various lengths of time. IL-19 significantly increased the accumulation of phospho-STAT3 and phospho-STAT6 in BMDMs (Figure 5, A and B). STAT6 has previously been shown to act as a facilitating factor for $\operatorname{PPAR} \gamma$, a nuclear hormone receptor transcription factor that reduces macrophage inflammation. ${ }^{28}$ To investigate whether
IL-19 regulates the expression of PPAR $\gamma$, we treated BMDMs and human macrophages with IL-19 and measured PPAR $\gamma$ expression. We found that IL-19 increased both PPAR $\gamma$ mRNA and protein expression in mouse and human macrophages (Figure 5, C-E). To determine whether IL-19-driven PPAR $\gamma$ expression is STAT dependent, two different STAT inhibitors were added to BMDMs at the time of IL-19 stimulation. Addition of STAT inhibitors significantly reduced IL-19-driven PPAR $\gamma$ protein abundance (Figure 5F). STAT inhibitors significantly reduced IL-19-driven expression of M2 marker mRNA for Ym1 (average, 89.5\%), Arg1 (average, 47.0\%), and PPAR $\gamma$ (average, 56.0\%) (Figure 5, G and $\mathrm{H}$ ).

To determine whether IL-19 increased PPAR $\gamma$ activity, we transfected a luciferase reporter vector driven by PPAR $\gamma$ activation elements into BMDMs and stimulated them with IL-19, the PPAR $\gamma$ activator Rosiglitazone, the PPAR $\gamma$ inhibitor GW9662, or combinations thereof. Importantly, IL19 alone significantly increased PPAR $\gamma$ activation twofold, an effect comparable with that of the PPAR $\gamma$ activator Rosiglitazone (Figure 5I). Addition of IL-19 and Rosiglitazone together increased PPAR $\gamma$ activation fivefold, and this was reduced by the PPAR $\gamma$ inhibitor GW9662 (Figure 5I). When taken together, both in vivo and ex vivo experiments suggest that IL-19 can activate molecular determinants of M2 polarization in macrophages. 


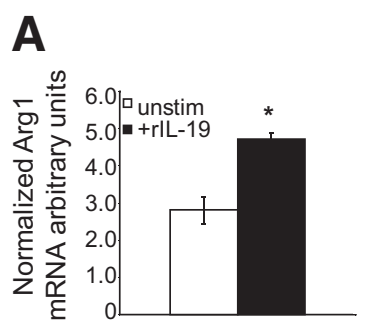

B

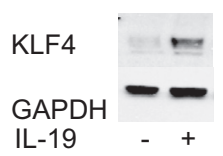

D

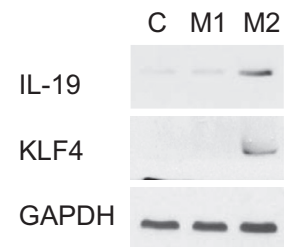

$\mathbf{F}$

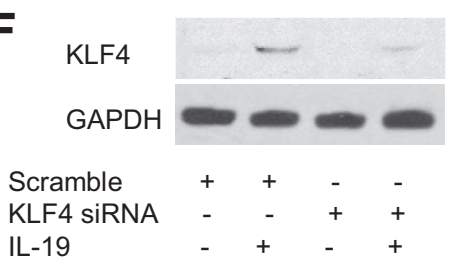

H

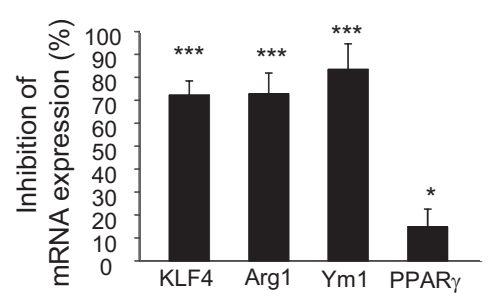

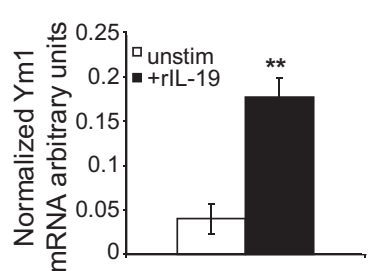

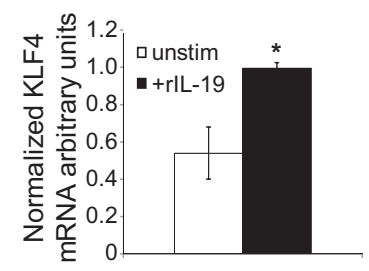

C
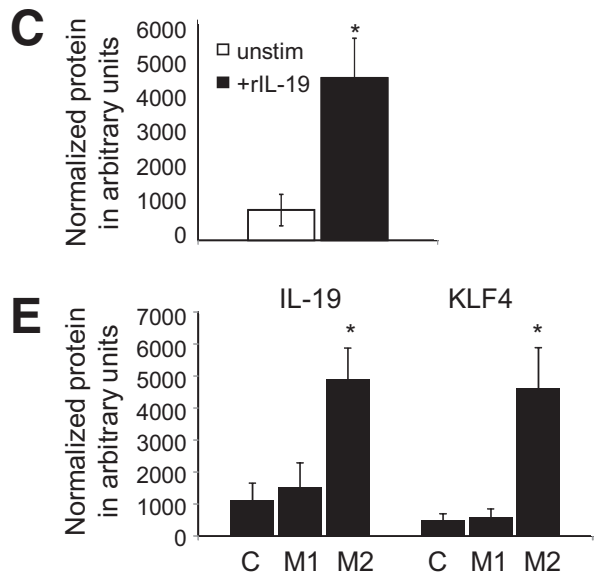

G

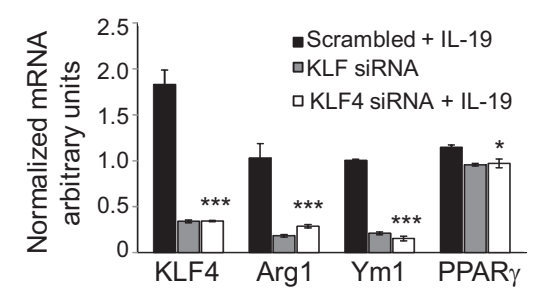

Figure 4 IL-19 polarization of BMDMs to M2 phenotype is KLF4 dependent. A: BMDMs were treated with IL-19 for 24 hours, RNA was subjected to RT-qPCR with the use of the primer pairs shown. B: Representative Western blot analysis of IL-19 induction of KLF4 expression. Lysates from BMDMs stimulated with IL-19 for the indicated time was immunoblotted with anti-KLF4 antibody. C: Densiometric quantification of independent Western blot analyses of BMDMs stimulated with IL-19 blotted for KLF4 protein expression. D: IL-19 expression is induced in human macrophages stimulated with M2 stimuli. Representative immunoblot showing lysates from human macrophages treated with IFN- $\gamma$ and LPS to induce M1, or IL-4 to induce the M2 phenotype, blotted with the indicated antibody. E: Densiometric quantification of independent Western blot analyses of BMDMs treated with IFN- $\gamma$ and LPS to induce M1, or IL-4 to induce the M2 phenotype, and blotted for IL-19 and KLF4 expression. KLF4 knockdown reduces IL-19-driven M2 polarization. F: KLF4 siRNA reduces IL-19-induced KLF4 protein abundance. G: BMDMs transfected with KLF4 siRNA were then stimulated with IL-19, and mRNA abundance for M2 associated genes were quantitated by RT-PCR. H: Percentage of inhibition was calculated from scrambled controls stimulated with IL-19. Data are expressed as means \pm SEM. $n=3$ independent Western blot analyses (C and $\mathbf{E})$, ${ }^{*} P<0.05,{ }^{* *} P<0.01$, and ${ }^{* * *} P<0.001$. BMDM, bone marrow-derived macrophage; $C$, control; IFN, interferon; KLF, Kruppel-like factor; LPS, lipopolysaccharide; PPAR, peroxisome proliferator-activated receptor; RT-qPCR, quantitative RT-PCR; unstim, unstimulated.

\section{IL-19 Alters Lipid Metabolism in Macrophages}

Macrophage uptake of modified lipid is a central step in plaque stasis and regression, and PPAR $\gamma$ has been reported to increase macrophage lipid uptake and efflux through modulation of key genes involved in lipid metabolism. To determine whether IL-19 could regulate macrophage lipid metabolism, BMDMs were pretreated with $100 \mathrm{ng} / \mathrm{mL}$ IL-19 for 8 hours, then incubated with 5 $\mu \mathrm{g} / \mathrm{mL}$ fluorescent Dil-oxLDL for 4 hours, at which time Dil-oxLDL uptake was quantitated by flow cytometry. IL19 significantly increased uptake of oxLDL in BMDMs by approximately $51 \%(449.7 \pm 27.3$ versus $678.3 \pm 17.8$ mean fluorescence intensity-Dil oxLDL; $P<0.0001$ ) (Figure 6A).

Previous studies have shown that the M2 macrophage phenotype is also characterized by an increase in scavenger receptor expression. ${ }^{22}$ To determine whether IL-19mediated changes in scavenger receptor expression underlie the increased uptake in oxLDL, we next measured mRNA levels of the predominant scavenger receptors expressed in macrophages. BMDMs stimulated with IL-19 for 24 hours showed an increase mRNA expression of CD36 $(0.86 \pm 0.1$ versus $1.21 \pm 0.01 ; P<0.001)$, SRA1 $(0.96 \pm 0.05$ versus $1.28 \pm 0.01 ; P<0.01)$, and SR-B1 $(1.01 \pm 0.06$ versus $2.33 \pm 0.11 ; P<0.01)$ (Figure 6, B-D). Importantly, IL-19 increased expression of these scavenger receptor proteins in both BMDMs and human macrophages at the protein level (Figure 6, E-G). Interestingly, STAT inhibitors did not reduce IL-19mediated increase in scavenger receptor expression (data not shown). This is the first report to show that IL-19 can increase oxLDL uptake in macrophages and suggests a potential mechanism for this increase. Excessive lipid 


\section{A}
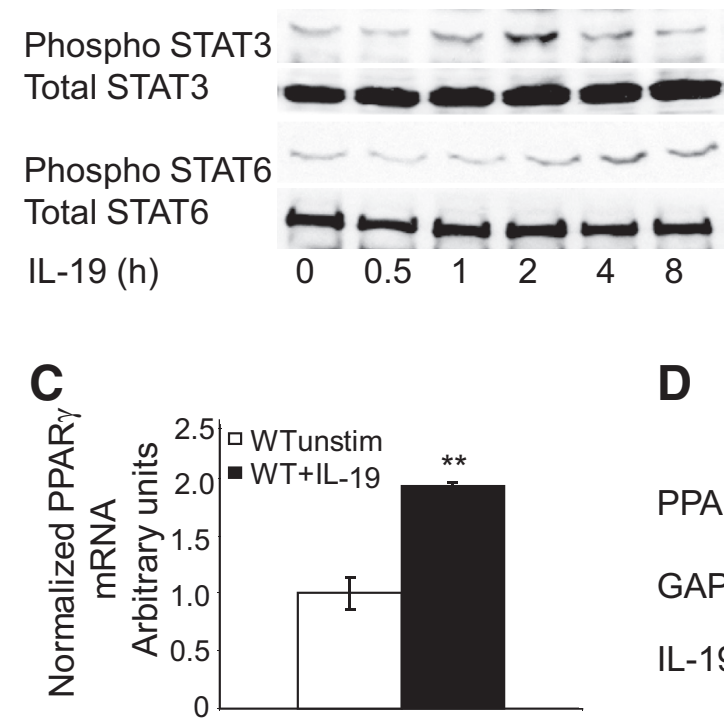

$\mathbf{F}$

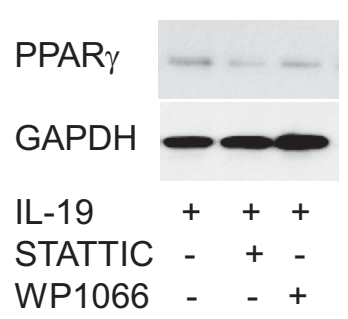

G
B

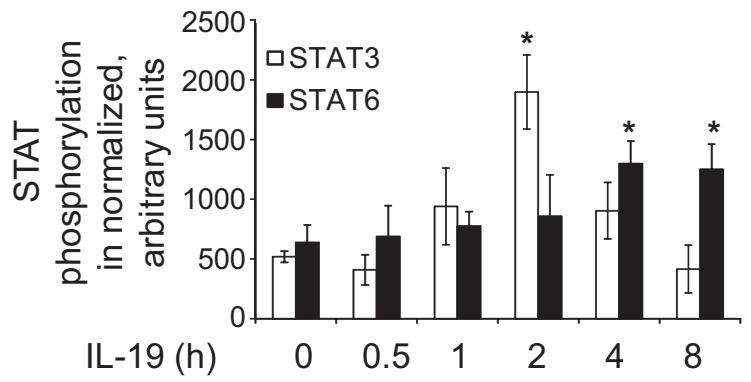

D

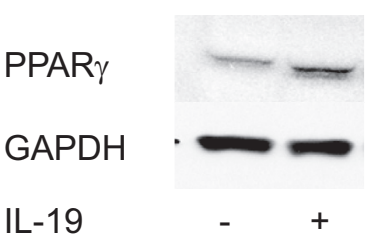

E

GAPDH

IL-19
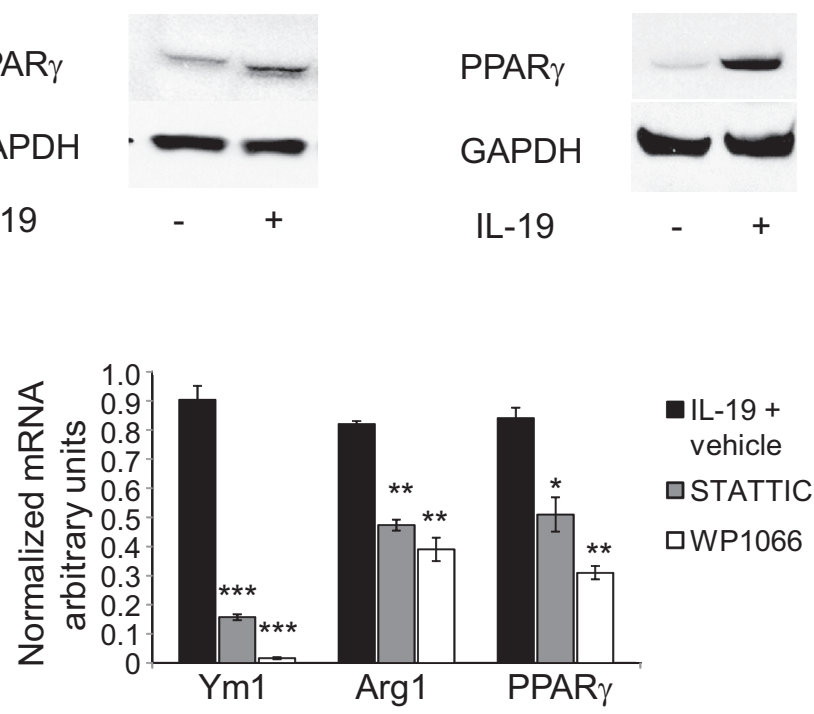

H

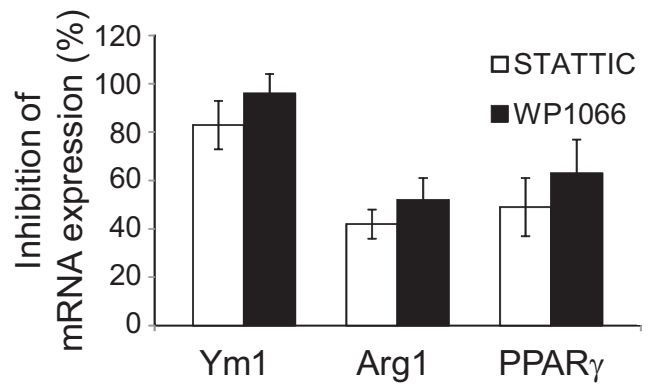

I

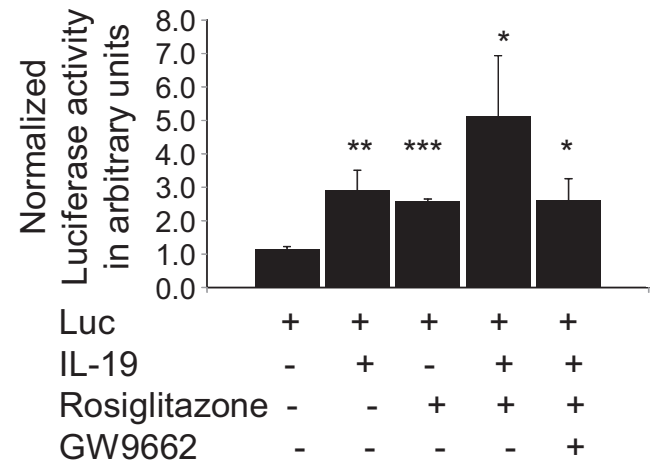

Figure 5 IL-19 activates STAT proteins and PPAR $\gamma$. A: Representative immunoblot of BMDMs stimulated with IL-19 for the indicated times. Extracts were blotted with anti-Phospho STAT3 (Tyr705), total STAT3, anti-phospho STAT6, or total STAT6. B: Densiometry was performed and values were normalized to total protein. C: IL-19 increases PPAR $\gamma$ mRNA expression. RNA isolated from BMDMs treated with IL-19 for 24 hours was subjected to quantitative RT-PCR with the use of PPAR $\gamma$-specific primers. D: IL-19 increases PPAR $\gamma$ protein expression. Lysates from BMDMs treated with IL-19 underwent Western blot analysis with the use of anti-PPAR $\gamma$ antibody. E: Lysates from human macrophages were treated with IL-19 and underwent Western blot analysis with the use of anti-PPAR $\gamma$ antibody. F: STAT inhibition reduces IL-19-driven PPAR $\gamma$ protein expression. Lysates from inhibitortreated BMDMs were blotted with the indicated antibody. G: STAT inhibition reduces IL-19-driven Ym1, Arg1, and PPAR $\gamma$ mRNA abundance. BMDMs treated with STAT-specific inhibitors were stimulated with IL-19, and mRNA abundance for M2 associated genes was quantitated by RT-PCR. H: Percentage of inhibition calculated from IL-19-stimulated vehicle controls. I: IL-19 activates PPAR $\gamma$ transcriptional activity. BMDMs were transfected with a PPAR $\gamma$ luciferase reporter plasmid and stimulated with IL-19, the PPAR $\gamma$ activator Rosiglitazone, the PPAR $\gamma$ inhibitor GW9664, or combinations thereof. PPAR $\gamma$ response element activation was quantitated by luciferase activity. Data are expressed as means \pm SEM. $n=3$ or more experiments (B); $n=3$ or more Western blot analyses $(\mathbf{D}-\mathbf{F}) .{ }^{*} P<0.05,{ }^{*} P<0.01$, and ${ }^{* *} P<0.001$. BMDM, bone marrow-derived macrophage; PPAR, peroxisome proliferator-activated receptor; unstim, unstimulated. 
A

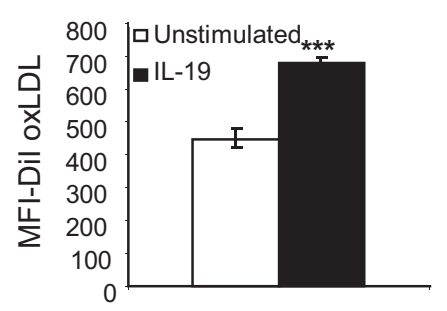

B

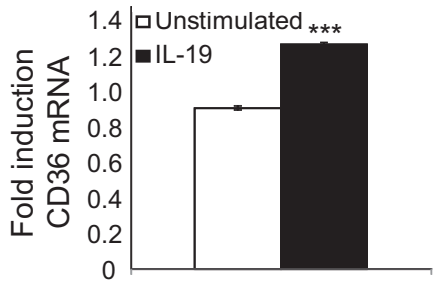

C

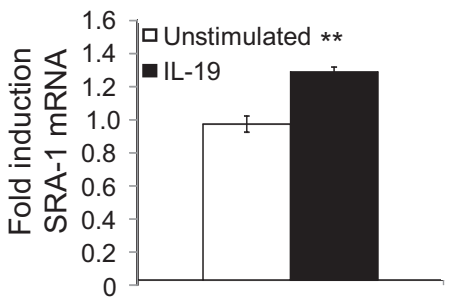

D

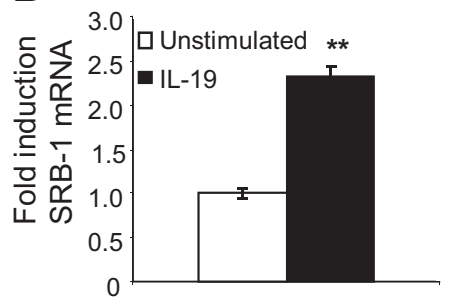

Figure 6 IL-19 induces cholesterol uptake and expression of lipid scavenger receptors. A: BMDMs isolated from wild-type C57B/6 mice were incubated with rIL-19, then with fluorescent Dil-oxLDL, and were washed, and cholesterol uptake was quantitated by flow cytometry. B-D: BMDMs were incubated with rIL-19 for the indicated times, and RNA was extracted and subjected to quantitative RT-PCR with the use of primers for the shown lipid scavenger receptors. E: Representative Western blot analysis of BMDMs treated with IL-19. Lysates made 24 hours after stimulation were subjected to Western blot analysis with the use of antibody for the shown lipid scavenger receptors. F: Densiometry was performed, and values were normalized to total protein G: Representative immunoblot of lysates from human macrophages treated with IL-19 blotted with antibody for the indicated lipid scavenger receptors. H: IL-19-driven increase in oxLDL uptake does not increase apoptosis. No significant difference in Casp3/7 luminescence is noted between IL19-treated and untreated groups. Data are expressed as means \pm SEM. $n=3$ experiments or more $(\mathbf{F}) .{ }^{*} P<0.05$, ${ }^{*} P<0.01$, and ${ }^{* * *} P<0.001$. BMDM, bone marrow-derived macrophage; Casp3/7, caspase 3/7; MFI, mean fluorescence intensity; oxLDL, oxidized low-density lipoprotein.
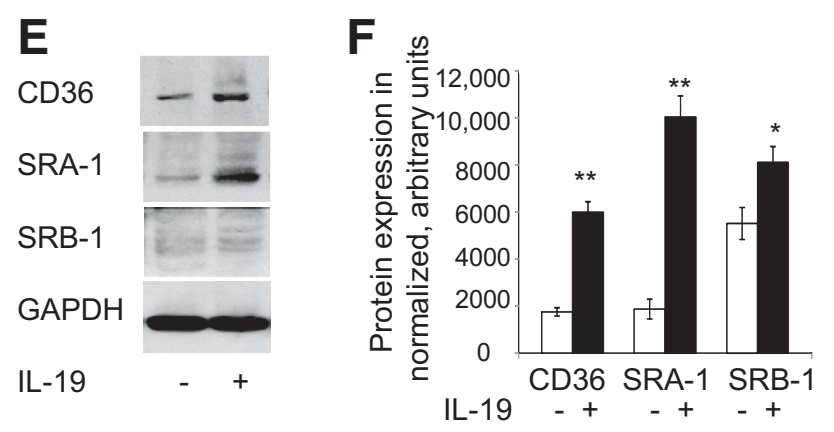

uptake induces apoptosis in lipid-laden macrophage. To test if the IL-19-induced increase in cholesterol uptake also increased apoptosis in macrophages, BMDMs were incubated with oxLDL, with and without IL-19. At all time points tested, IL-19 had no significant effect on apoptosis, as measured by Caspase luminescence (Figure 6H).

\section{IL-19 Regulates Cholesterol Metabolism by PPAR $\gamma$}

PPAR $\gamma$ can regulate cholesterol homeostasis by transcriptional activation of scavenger receptors and the cholesterol transporter ABCA1. ${ }^{8,10,11,28,29}$ We hypothesized that IL-19 effects on cholesterol uptake and receptor expression were PPAR $\gamma$ dependent. To test this hypothesis, we first silenced PPAR $\gamma$ expression by transfection of BMDMs with PPAR $\gamma$-specific siRNA. The ability of IL-19 to increase scavenger receptor expression was lost in cells in which PPAR $\gamma$ was knocked down (Figure 7, A and B). Consistent with this finding, the IL-19-mediated increase in oxLDL uptake in BMDMs was abrogated in BMDMs in which PPAR $\gamma$ expression was reduced by siRNA (Figure 7C). Together, these results suggest that the IL-19-mediated increase in scavenger receptor expression and cholesterol uptake in BMDMs are driven by PPAR $\gamma$.
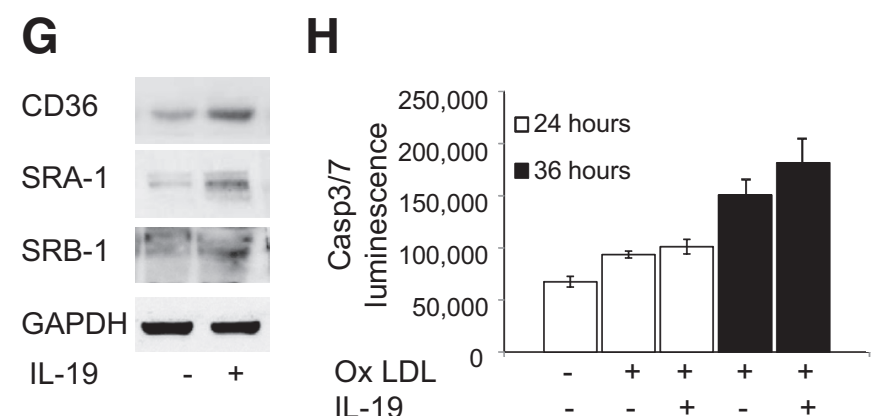

In addition to regulating scavenger receptor-mediated cholesterol uptake, PPAR $\gamma$ is known to balance macrophage lipid metabolism by increasing cholesterol efflux. To investigate whether IL-19-mediated regulation of PPAR $\gamma$ can also alter macrophage cholesterol export we first measured expression of the cholesterol transporters ABCA1 and ABCG1. Notably, BMDMs stimulated with IL-19 for 24 hours showed increased expression of ABCA1 and ABCG1 at both the mRNA and protein levels (Figure 8, A-C). Furthermore, the ability of IL-19 to induce ABCA1 and ABCG1 expression was lost in cells in which PPAR $\gamma$ was knocked down (Figure 8, $\mathrm{D}$ and $\mathrm{E}$ ), indicating a key role for PPAR $\gamma$ in mediating these IL-19-dependent effects. Most importantly, the IL19-dependent increase in ABCA1 was functionally relevant, because IL-19-treated BMDMs showed a significant increase in apoA1-dependent cholesterol efflux $(5.27 \% \pm 0.22 \%$ versus $8.09 \% \pm 0.52 \%$ for control and IL-19 treated, respectively; $P<0.05$ ) (Figure 8F), which is noteworthy because increased cholesterol efflux is a known atheroprotective mechanism.

\section{Discussion}

The major novel findings of this study are that IL-19 halts plaque progression, polarizes macrophages to the M2 
phenotype within the proinflammatory background of hyperlipidemia, induces the expression of macrophage scavenger receptors and modified LDL endocytosis in a PPAR $\gamma$-dependent mechanism, and enhances the expression of macrophage cholesterol transporters and promotes cholesterol efflux. This has translational implications in that two proposed mechanisms of plaque regression are modulation of cholesterol transport $^{8,27,30}$ and M2 polarization of macrophage. ${ }^{3,4}$ Although an increase in some components of the IL-10 signaling pathway has been correlated with conjugated linoleic acid-induced plaque regression, ${ }^{21}$ to the best of our knowledge, this is the first report of a Th2 interleukin causing stasis of preformed plaque.

Similar to IL-10, IL-19 does not significantly alter circulating lipoprotein levels, and we focused on potential immunologic effects of IL-19.30,31 Changes in the local cytokine milieu can trigger the conversion of intraplaque macrophage to M1. ${ }^{32}$ In this study we show that addition of IL-19 to BMDMs decreases TNF- $\alpha$-driven expression of inflammatory cytokines, which may represent an antiatherogenic mechanism mediated by IL-19.

In vivo, both aorta and spleen from $\mathrm{LDLR}^{-1-}$ mice injected with rIL-19 showed an increase in macrophage M2 markers. This suggests that even within the background of an atherogenic diet, which is recognized to drive proinflammatory processes, both locally within the aorta and systemically within the spleen, IL-19 can polarize macrophages to the M2 phenotype. This is consistent with reports showing that in regressing plaque, plaque macrophages are polarized toward the M2 phenotype. ${ }^{1,3,27}$ In the current report, studies in which IL-19 was added to cultured BMDMs also showed increased expression of M2 phenotype markers, suggesting direct effects of IL-19 on macrophage polarization. Cultured macrophages can be M2 polarized independent of IL-4 and IL-13, ${ }^{33}$ suggesting that macrophage polarization by IL-19 may be a previously unrecognized M2 stimulus and a potential mechanism of how IL-19 contributes to plaque stasis. Future studies should characterize in detail IL-19 effects on immune cell populations.
IL-19 activates STAT3, which is noteworthy because IL-10-mediated STAT3 activation is associated with an M2 macrophage phenotype. ${ }^{22,25-27}$ We report here that IL-19 also activates STAT6. STAT6 phosphorylation activates transcription of genes associated with M2 phenotype such as KLF4, Arg1, and PPAR $\gamma .{ }^{28,34}$ Rapid activation of STAT proteins by IL-19 may be the initial steps in IL-19 macrophage polarization.

Proinflammatory cytokines (eg, IL-1 $\beta$, MCP-1) are known to decrease uptake. ${ }^{35,36}$ Thus, increased uptake of oxidized lipids by the macrophage could be considered an atheroprotective mechanism to reduce plaque formation. The role of Th2 cytokines in macrophage lipid homeostasis is unresolved. Previous studies that focused primarily on the archetypical Th2 cytokine IL-10 vary, because in some studies it increases cholesterol uptake and efflux in macrophages, ${ }^{37,38}$ whereas in other studies IL-10 decreases oxLDL uptake and CD36 expression. ${ }^{39}$ Our study is the first to report that IL-19 can increase macrophage cholesterol uptake, with the likely mechanism the IL-19-driven expression of CD36, SRA-1, and SRB-1, which are key participants in the uptake of modified lipid in macrophages. This is similar to the studies which maintain that IL-10 increases cholesterol uptake and efflux in the macrophage in a PPAR $\gamma$-dependent mechanism. Interestingly, the study which suggested that IL-10 decreased oxLDL uptake indicated that it did so because IL-10 decreased CD36 expression and inhibited PPAR $\gamma$ activation. ${ }^{39}$ Expression of these receptors are important because CD36, SRB-1, and SRA-1 have been shown to be atheroprotective. ${ }^{8}$ IL-19-induced increase in CD36 expression is particularly noteworthy in that CD36 contributes up to $70 \%$ of cholesterol accumulation in the macrophage., ${ }^{9,39}$ An additional protective role for CD36 is its ability to activate PPAR $\gamma$ expression. ${ }^{40}$ Studies suggest that overexpression of SRA-1 in both ApoE and LDLR mice reduces atherosclerosis, ${ }^{41-44}$ and deletion of SRA-1 bred into $\mathrm{ApoE}^{-1-}$ mice significantly increased atherosclerosis. $^{44,45}$ SRB-1 is also considered to be
A

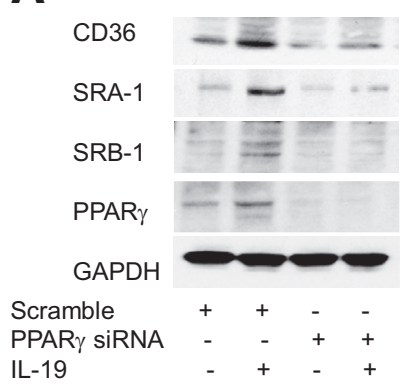

B

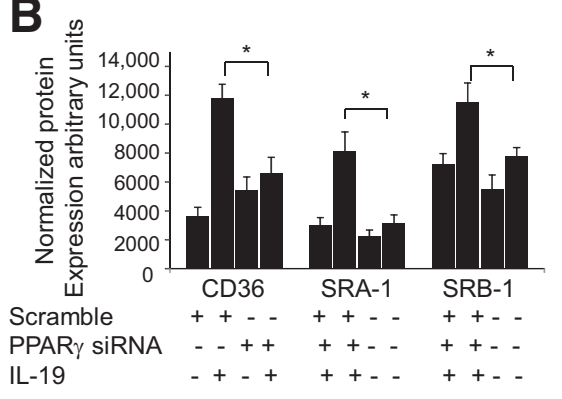

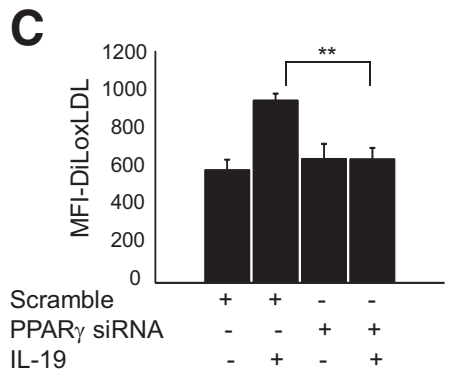

IL-19

Figure 7 IL-19 regulates cholesterol metabolism via PPAR $\gamma$. A: BMDMs transfected with PPAR $\gamma$ siRNA effectively reduce PPAR $\gamma$ protein expression, and PPAR $\gamma$ knockdown reduces IL-19-mediated expression of cholesterol uptake receptors. BMDMs transfected with PPAR $\gamma$ siRNA were treated with rIL-19 for 24 hours, then underwent Western blot analysis for the indicated cholesterol scavenger receptors with the use of specific antibody. B: Quantitation of protein expression by densiometry. C: PPAR $\gamma$ knockdown reduces IL-19-mediated cholesterol uptake. BMDMs were transfected with PPAR $\gamma$ siRNA, then treated with rIL-19, then with fluorescent DiL-oxLDL, washed, and uptake was quantitated by flow cytometry. Data are expressed as means \pm SEM. $n=3$ or more Western blot analyses. ${ }^{*} P<0.05$ for scrambled control versus siRNA; ${ }^{* \star} P<0.01$. BMDM, bone marrow-derived macrophage; MFI, mean fluorescence intensity; oxLDL, oxidized low-density lipoprotein; PPAR, peroxisome proliferator-activated receptor. 
A

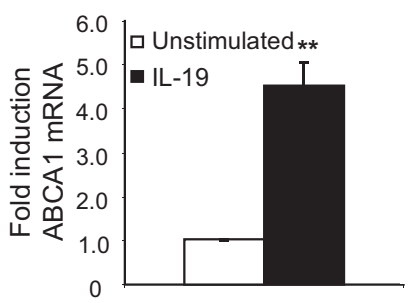

C
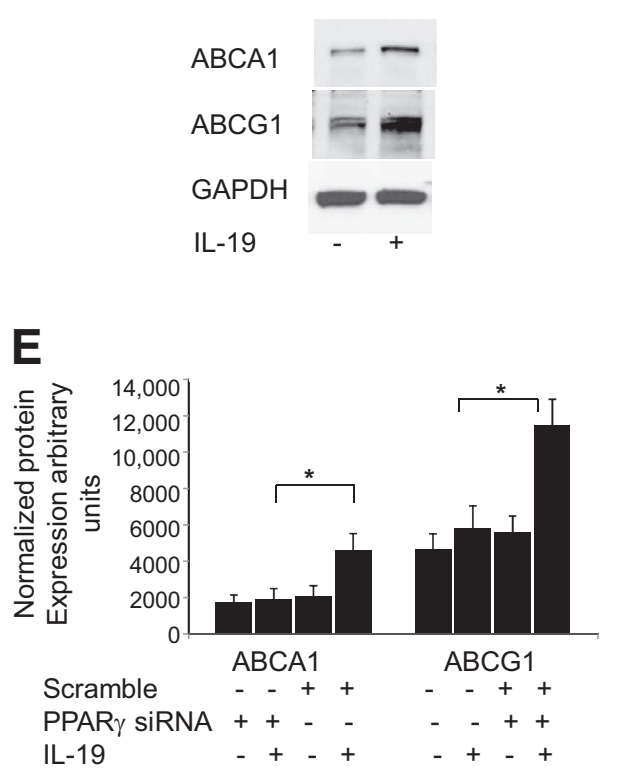

B

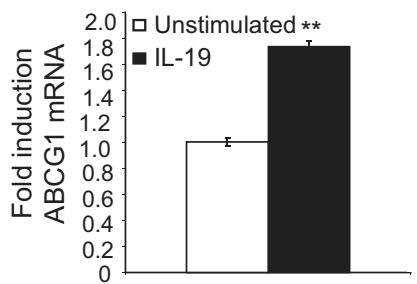

D

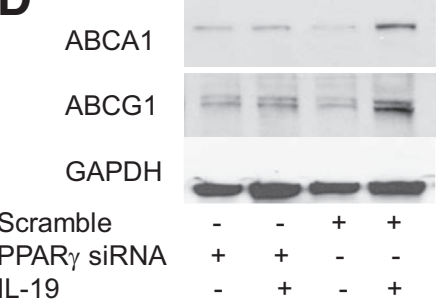

$\mathbf{F}$

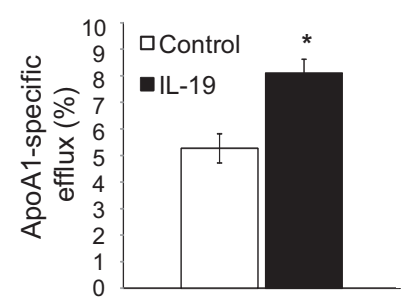

Figure 8 IL-19 induces cholesterol uptake and expression of cholesterol transport proteins. $\mathbf{A}$ and B: BMDMs was incubated with rIL-19 for the indicated times, RNA was extracted and subjected to quantitative RT-PCR with the use of primers for the shown cholesterol transport proteins. C: Representative Western blot analysis of BMDMs treated with IL-19. Lysates made 24 hours after stimulation were subjected to Western blot analysis with the use of antibody for the shown cholesterol transport proteins. D: BMDMs transfected with PPAR $\gamma$ siRNA effectively reduces IL-19-mediated expression of cholesterol transport proteins. E: Densiometry was performed, and values were normalized to total protein F: IL-19 induces cholesterol efflux. BMDMs were incubated with acLDL, then 16 hours with or without IL-19. Cells were incubated with apoA1, in the presence or absence of IL-19, and efflux to ApoA1 was quantitated. Data are expressed as means \pm SEM. $n=3$ or more experiments (E). ${ }^{*} P<0.05,{ }^{*} P<0.01$. apoA1, apolipoprotein $\mathrm{A} 1$; BMDM, bone marrow-derived macrophage; LDL, low-density lipoprotein. atheroprotective, because SRB-1/ApoE ${ }^{-/-}$double knockout mice develop increased atherosclerosis, ${ }^{46,47}$ and overexpression of SRB-1 protects against atherosclerosis in LDLR mice. ${ }^{48}$ IL-19 increase in lipid receptor expression is also consistent with reports showing that the M2 macrophage phenotype is characterized by an increase in scavenger receptor expression. ${ }^{22}$ Conversely, stimulation of macrophages with the M1 stimulus IFN- $\gamma$ decreases CD36 and SRA1 expression and decreases cholesterol uptake. ${ }^{49}$

Macrophages participate in reverse cholesterol transport by effluxing accumulated cholesterol which involves both ABCA1 and ABCG1 transporters and is a potent atheroprotective event, because disruption of either of these transporters results in exacerbated plaque burden. ${ }^{50,51}$ IL-10 treatment of macrophages do not increase expression of these transporters; however, transporter mRNA expression is increased in IL-10 transgenic macrophages. ${ }^{37,38}$ Together, the ability of IL-19 to promote macrophage lipid uptake and efflux, through increased scavenger receptor and cholesterol transporter expression, may represent an additional major mechanism of how IL-19 contributes to plaque stasis.

From a mechanistic standpoint, perhaps the most important observation from the current study is that IL-19 induces PPAR $\gamma$ expression and PPAR $\gamma$ activation, and that knockdown of PPAR $\gamma$ abrogates IL-19-mediated induction of scavenger receptor expression and IL-19-mediated lipid uptake. Use of a PPAR $\gamma$ inhibitor reduced IL-10-mediated cholesterol efflux, but IL-10-induced expression of PPAR $\gamma$ was not observed in this study. ${ }^{38}$ PPAR $\gamma$ is an antiinflammatory transcription factor that regulates cholesterol homeostasis by modulation of scavenger receptor proteins. ${ }^{29}$ PPAR $\gamma$ agonists ameliorate inflammation, induce the regression of established atherosclerotic plaque. ${ }^{3}$ PPAR $\gamma$ expression is also elevated in the M2 phenotype. $^{3,27}$ Disruption of PPAR $\gamma$ results in decreased expression of receptor and transporter proteins and a concomitant reduction in oxLDL uptake. ${ }^{10,11}$ This study places IL-19 proximal to activation of this important anti-inflammatory transcription factor.

When taken in aggregate, we have identified a novel pathway in which IL-19 activates STAT3 and STAT6 and increases expression and activation of PPAR $\gamma$ and other M2 markers, resulting in an increase in expression of lipid scavenger receptor expression and a concomitant increase in macrophage cholesterol uptake and efflux. This suggests that IL-19 is a previously unrecognized link between inflammatory processes and macrophage cholesterol homeostasis.

\section{References}

1. Sica A, Mantovani A: Macrophage plasticity and polarization: in vivo veritas. J Clin Invest 2012, 122:787-795 
2. Fredman G, Spite M: Recent advances in the role of immunity in atherosclerosis. Circ Res 2013, 113:e111-e114

3. Feig JE, Parathath S, Rong JX, Mick SL, Vengrenyuk Y, Grauer L, Young SG, Fisher EA: Reversal of hyperlipidemia with a genetic switch favorably affects the content and inflammatory state of macrophages in atherosclerotic plaques. Circulation 2011, 123:989-998

4. Francis AA, Pierce GN: An integrated approach for the mechanisms responsible for atherosclerotic plaque regression. Exp Clin Cardiol 2011, 16:77-86

5. Glass CK, Witztum JL: Atherosclerosis; the road ahead. Cell 2001, 104:503-516

6. Kzhyshkowska J, Neyen C, Gordon S: Role of macrophage scavenger receptors in atherosclerosis. Immunobiology 2012, 217:492-502

7. Kunjathoor VV, Febbraio M, Podrez EA, Moore KJ, Andersson L, Koehn S, Rhee JS, Silverstein R, Hoff HF, Freeman MW: Scavenger receptors class A-I/II and CD36 are the principal receptors responsible for the uptake of modified low density lipoprotein leading to lipid loading in macrophages. J Biol Chem 2002, 277:49982-49988

8. Moore KJ, Freeman MW: Scavenger receptors in atherosclerosis: beyond lipid uptake. Arterioscler Thromb Vasc Biol 2006, 26: $1702-1711$

9. Castrillo A, Tontonoz P: Nuclear receptors in macrophage biology: at the crossroads of lipid metabolism and inflammation. Annu Rev Cell Dev Biol 2004, 20:455-480

10. Chawla A, Boisvert WA, Lee CH, Laffitte BA, Barak Y, Joseph SB, Liao D, Nagy L, Edwards PA, Curtiss LK, Evans RM, Tontonoz PA: PPAR gamma-LXR-ABCA1 pathway in macrophages is involved in cholesterol efflux and atherogenesis. Mol Cell 2001, 7:161-171

11. Akiyama TE, Sakai S, Lambert G, Nicol CJ, Matsusue K, Pimprale S, Lee YH, Ricote M, Glass CK, Brewer HB Jr, Gonzalez FJ: Conditional disruption of the peroxisome proliferator-activated receptor gamma gene in mice results in lowered expression of ABCA1, ABCG1, and apoE in macrophages and reduced cholesterol efflux. Mol Cell Biol 2002, 22:2607-2619

12. Gallagher $\mathrm{G}$, Dickensheets H, Eskdale J, Izotova LS, Mirochnitchenko OV, Peat JD, Vazquez N, Pestka S, Donnelly RP, Kotenko SV: Cloning, expression and initial characterization of interleukin-19 (IL-19), a novel homologue of human interleukin-10 (IL-10). Genes Immun 2000, 1:442-450

13. Oral HB, Kotenko SV, Yilmaz M, Mani O, Zumkehr J, Blaser K, Akdis CA, Akdis M: Regulation of T cells and cytokines by the interleukin-10 (IL-10)-family cytokines IL-19, IL-20, IL-22, IL-24 and IL-26. Eur J Immunol 2006, 36:380-388

14. Gallagher G, Eskdale J, Jordan W, Peat J, Campbell J, Boniotto M, Lennon GP, Dickensheets H, Donnelly RP: Human interleukin-19 and its receptor: a potential role in the induction of $\mathrm{Th} 2$ responses. Int Immunopharmacol 2004, 4:615-626

15. Ellison S, Gabunia K, Kelemen SE, England RN, Scalia R, Richards JM, Orr AW, Traylor JG Jr, Rogers T, Cornwell W, Berglund LM, Goncalves I, Gomez MF, Autieri MV: Attenuation of experimental atherosclerosis by interleukin-19. Arterioscler Thromb Vasc Biol 2013, 33:2316-2324

16. Gallagher G: Interleukin-19: multiple roles in immune regulation and disease. Cytokine Growth Factor Rev 2010, 21:345-352

17. Tian Y, Sommerville LJ, Cuneo A, Kelemen SE, Autieri MV: Expression and suppressive effects of interleukin-19 on vascular smooth muscle cell pathophysiology and development of intimal hyperplasia. Am J Pathol 2008, 173:901-909

18. Gabunia K, Jain S, England RN, Autieri MV: Anti-inflammatory cytokine interleukin-19 inhibits smooth muscle cell migration and activation of cytoskeletal regulators of VSMC motility. Am J Physiol Cell Physiol 2011, 300:C896-C906

19. Cuneo AA, Herrick D, Autieri MV: IL-19 reduces VSMC activation by regulation of mRNA regulatory factor HuR and reduction of mRNA stability. J Mol Cell Cardiol 2010, 49:647-654

20. Xu S, Huang Y, Xie Y, Lan T, Le K, Chen J, Chen S, Gao S, Xu X, Shen $\mathrm{X}$, Huang H, Liu P: Evaluation of foam cell formation in cultured macrophages: an improved method with Oil Red O staining and DiI-oxLDL uptake. Cytotechnology 2010, 62:473-481

21. Daugherty A, Rateri DL: Development of experimental designs for atherosclerosis studies in mice. Methods 2005, 36:129-138

22. Mantovani A, Sozzani S, Locati M, Allavena P, Sica A: Macrophage polarization: tumor-associated macrophages as a paradigm for polarized M2 mononuclear phagocytes. Trends Immunol 2002, 23: 549-555

23. Schust J, Sperl B, Hollis A, Mayer TU, Berg T: Stattic: a smallmolecule inhibitor of STAT3 activation and dimerization. Chem Biol 2006, 13:1235-1242

24. Hussain SF, Kong LY, Jordan J, Conrad C, Madden T, Fokt I, Priebe W, Heimberger AB: A novel small molecule inhibitor of signal transducers and activators of transcription reverses immune tolerance in malignant glioma patients. Cancer Res 2007, 67:9630-9636

25. Lang R, Patel D, Morris JJ, Rutschman RL, Murray PJ: Shaping gene expression in activated and resting primary macrophages by IL-10. J Immunol 2002, 169:2253-2263

26. Gordon S: Alternative activation of macrophages. Nat Rev Immunol 2003, 3:23-35

27. Khallou-Laschet J, Varthaman A, Fornasa G, Compain C, Gaston AT, Clement M, Dussiot M, Levillain O, Graff-Dubois S, Nicoletti A, Caligiuri G: Macrophage plasticity in experimental atherosclerosis. PLoS One 2010, 25:e8852

28. Szanto A, Balint BL, Nagy ZS, Barta E, Dezso B, Pap A, Szeles L, Poliska S, Oros M, Evans RM, Barak Y, Schwabe J, Nagy L: STAT6 transcription factor is a facilitator of the nuclear receptor PPAR $\gamma$ regulated gene expression in macrophages and dendritic cells. Immunity 2010, 33:699-712

29. Murphy JE, Tedbury PR, Homer-Vanniasinkam S, Walker JH, Ponnambalam S: Biochemistry and cell biology of mammalian scavenger receptors. Atherosclerosis 2005, 182:1-15

30. Williams KJ, Feig JE, Fisher EA: Cellular and molecular mechanisms for rapid regression of atherosclerosis: from bench top to potentially achievable clinical goal. Curr Opin Lipidol 2007, 18: 443-450

31. McCarthy C, Duffy MM, Mooney D, James WG, Griffin MD, Fitzgerald DJ, Belton O: IL-10 mediates the immunoregulatory response in conjugated linoleic acid-induced regression of atherosclerosis. FASEB J 2013, 27:499-510

32. Pinderski LJ, Fischbein MP, Subbanagounder G, Fishbein MC, Kubo N, Cheroutre H, Curtiss LK, Berliner JA, Boisvert WA: Overexpression of interleukin-10 by activated $\mathrm{T}$ lymphocytes inhibits atherosclerosis in LDL receptor-deficient Mice by altering lymphocyte and macrophage phenotypes. Circ Res 2002, 90:1064-1071

33. Dupasquier M, Stoitzner P, Wan H, Cerqueira D, van Oudenaren A, Voerman JS, Denda-Nagai K, Irimura T, Raes G, Romani N, Leenen PJ: The dermal microenvironment induces the expression of the alternative activation marker CD301/mMGL in mononuclear phagocytes, independent of IL-4/IL-13 signaling. J Leukoc Biol 2006, 80:838-849

34. Lu M, Sarruf DA, Talukdar S, Sharma S, Li P, Bandyopadhyay G, Nalbandian S, Fan W, Gayen JR, Mahata SK, Webster NJ, Schwartz MW, Olefsky J: Brain PPAR- $\gamma$ promotes obesity and is required for the insulin-sensitizing effect of thiazolidinediones. Nat Med 2011, 17:618-622

35. Persson J, Nilsson J, Lindholm MW: Cytokine response to lipoprotein lipid loading in human monocyte-derived macrophages. Lipids Health Dis 2006, 5:17

36. Podrez EA, Febbraio M, Sheibani N, Schmitt D, Silverstein RL, Hajjar DP, Cohen PA, Frazier WA, Hoff HF, Hazen SL: Macrophage scavenger receptor CD36 is the major receptor for LDL modified by monocyte-generated reactive nitrogen species. J Clin Invest 2000, 105:1095-1108

37. Han X, Kitamoto S, Wang H, Boisvert WA: Interleukin-10 overexpression in macrophages suppresses atherosclerosis in hyperlipidemic mice. FASEB J 2010, 24:2869-2880 
38. Han X, Kitamoto S, Lian Q, Boisvert WA: Interleukin-10 facilitates both cholesterol uptake and efflux in macrophages. J Biol Chem 2009, 284:32950-32958

39. Rubic T, Lorenz RL: Downregulated CD36 and oxLDL uptake and stimulated ABCA1/G1 and cholesterol efflux as antiatherosclerotic mechanisms of interleukin-10. Cardiovasc Res 2006, 69:527-535

40. Nagy L, Tontonoz P, Alvarez JG, Chen H, Evans RM: Oxidized LDL regulates macrophage gene expression through ligand activation of PPARgamma. Cell 1998, 93:229-240

41. Whitman SC, Rateri DL, Szilvassy SJ, Cornicelli JA, Daugherty A: Macrophage-specific expression of class A scavenger receptors in LDL receptor(-/-) mice decreases atherosclerosis and changes spleen morphology. J Lipid Res 2002, 43:1201-1208

42. Van Eck M, De Winther MP, Herijgers N, Havekes LM, Hofker MH, Groot PH, Van Berkel TJ: Effect of human scavenger receptor class A overexpression in bone marrow-derived cells on cholesterol levels and atherosclerosis in ApoE-deficient mice. Arterioscler Thromb Vasc Biol 2000, 20:2600-2606

43. Herijgers N, de Winther MP, Van Eck M, Havekes LM, Hofker MH, Hoogerbrugge PM, Van Berkel TJ: Effect of human scavenger receptor class A overexpression in bone marrow-derived cells on lipoprotein metabolism and atherosclerosis in low density lipoprotein receptor knockout mice. J Lipid Res 2000, 41:1402-1409

44. Moore KJ, Kunjathoor VV, Koehn SL, Manning JJ, Tseng AA Silver JM, McKee M, Freeman MW: Loss of receptor-mediated lipid uptake via scavenger receptor A or CD36 pathways does not ameliorate atherosclerosis in hyperlipidemic mice. J Clin Invest 2005 , 115:2192-2201

45. de Winther MP, Gijbels MJ, van Dijk KW, van Gorp PJ, Suzuki H, Kodama T, Frants RR, Havekes LM, Hofker MH: Scavenger receptor deficiency leads to more complex atherosclerotic lesions in APOE3Leiden transgenic mice. Atherosclerosis 1999, 144:315-321

46. Braun A, Trigatti BL, Post MJ, Sato K, Simons M, Edelberg JM, Rosenberg RD, Schrenzel M, Krieger M: Loss of SR-BI expression leads to the early onset of occlusive atherosclerotic coronary artery disease, spontaneous myocardial infarctions, severe cardiac dysfunction, and premature death in apolipoprotein E-deficient mice. Circ Res 2002, 90:270-276

47. Mardones P, Quiñones V, Amigo L, Moreno M, Miquel JF, Schwarz M, Miettinen HE, Trigatti B, Krieger M, VanPatten S, Cohen DE, Rigotti A: Hepatic cholesterol and bile acid metabolism and intestinal cholesterol absorption in scavenger receptor class B type I-deficient mice. J Lipid Res 2001, 42:170-180

48. Kozarsky KF, Donahee MH, Glick JM, Krieger M, Rader DJ: Gene transfer and hepatic overexpression of the HDL receptor SR-BI reduces atherosclerosis in the cholesterol-fed LDL receptor-deficient mouse. Arterioscler Thromb Vasc Biol 2000, 20:721-727

49. Nakagawa T, Nozaki S, Nishida M, Yakub JM, Tomiyama Y, Nakata A, Matsumoto K, Funahashi T, Kameda-Takemura K, Kurata Y, Yamashita S, Matsuzawa Y: Oxidized LDL increases and interferongamma decreases expression of CD36 in human monocyte-derived macrophages. Arterioscler Thromb Vasc Biol 1998, 18:1350-1357

50. van Eck M, Bos IS, Kaminski WE, Orsó E, Rothe G, Twisk J, Böttcher A, Van Amersfoort ES, Christiansen-Weber TA, FungLeung WP, Van Berkel TJ, Schmitz G: Leukocyte ABCA1 controls susceptibility to atherosclerosis and macrophage recruitment into tissues. Proc Natl Acad Sci U S A 2002, 99:6298-6303

51. Kennedy MA, Barrera GC, Nakamura K, Baldán A, Tarr P, Fishbein MC, Frank J, Francone OL, Edwards PA: ABCG1 has a critical role in mediating cholesterol efflux to HDL and preventing cellular lipid accumulation. Cell Metab 2005, 1:121-131 